\title{
YVES SAINT LAURENT: COLEÇÃO POP ART E A CRIAÇÃO DO LE SMOKING PARA O OUTONO-INVERNO DE 1966
}

\section{YVES SAINT LAURENT: POP ART COLLECTION AND THE CREATION OF LE SMOKING FOR AUTUMN-WINTER 1966}

Mariana Mayumi Abe Oliveira ${ }^{1}$

Resumo: Este artigo analisa o impacto e a importância da criação do le smoking por Yves Saint Laurent, na França em 1966, através de uma discussão sobre a representação, a simbologia e o imaginário na sociedade do período. A partir da realização de pesquisas em periódicos da época (1965-1975), buscamos compreender o contexto social, cultural e econômico e destacar a importância do estudo da indumentária no meio historiográfico, assim como a influência da moda enquanto vertente transformadora de pensamentos e posicionamentos.

Palavras-chave: Moda; Indumentária; Yves Saint Laurent; Haute Couture; História da França.

Abstract: This article analyzes the impact and importance of the creation of le smoking by Yves Saint Laurent in France in 1966, through a discussion about representation, symbology and the imaginary in the society of the period. Through researches in periodicals of the time (1965-1975), we seek to understand the social, cultural and economic contexts, as well as to highlight the importance of the study of clothing in the historiographic environment and the influence of fashion as a transforming aspect of thoughts and positions.

Keywords: Fashion; Dressing; Yves Saint Laurent; Haute Couture; France History.

${ }^{1}$ Graduanda no curso de História (Licenciatura) pela Pontifícia Universidade Católica do Paraná. Email para contato: mariana.mayumii@gmail.com. 


\section{Introdução}

Desde muito cedo na história humana, o vestuário aparece como uma das partes intrínsecas que definem e acompanham as mudanças ocorridas ao longo dos séculos nas sociedades ao redor do mundo. Desta forma, o estudo da indumentária e da moda adquire grande valor, por analisar e buscar compreender qual o papel do vestuário e seus diversos hábitos, em diferentes períodos da humanidade.

A importância do vestuário dentro da estrutura social se modifica conforme a sociedade e o período analisado, podendo variar dentro de parâmetros mais simples como o de algo aparentemente "não pensado", sem valor - um pedaço de pano que serve somente para cobrir e aquecer o corpo - e podendo chegar até grandes ícones de status social, político e/ou financeiro que representam simbolicamente em certas sociedades altos níveis de importância dentro das hierarquias e do status quo.

Diane Crane delineia de maneira breve em seu livro sua definição de vestuário e moda, caracterizando também a sua função social:

A escolha do vestuário propicia um excelente campo para estudar como as pessoas interpretam determinada forma de cultura para seu próprio uso, forma essa que inclui normas rigorosas sobre a aparência que se considera apropriada num determinado período (o que é conhecido como moda), bem como uma variedade de alternativas extraordinariamente rica. Sendo uma das mais evidentes marcas de status social e de gênero - útil, portanto, para manter ou subverter fronteiras simbólicas -, o vestuário constituiu uma indicação de como as pessoas, em diferentes épocas, veem sua posição nas estruturas sociais e negociam as fronteiras de status (CRANE, 2009: 21). 
As simbologias caminham lado a lado com a moda, em diversos graus e diferentes importâncias conforme o período, mas sempre com intenções direcionadas. Pesavento (1995: 24) entende que "o imaginário social se expressa por símbolos, ritos, crenças, discursos e representações alegóricas figurativas", que podem ser traduzidos para a moda por meio do controle social, de classe e de gênero, pela busca de representatividade, como uma forma de protesto, ou ainda, de diversas outras maneiras de expor, por meio da moda, uma intencionalidade.

Em contrapartida, mesmo com o conceito de moda distintamente conhecido no âmbito social, assim como os estudos feitos na área sendo amplamente discutidos, a indumentária ainda acaba por ser considerada de "segunda classe" no meio acadêmico quanto à sua importância e ao impacto na historiografia. Gilles Lipovetsky aponta em sua obra $O$ Império do Efêmero, sobre a existência desta dicotomia:

A moda é celebrada no museu, é relegada à antecâmara das preocupações intelectuais reais; está por toda parte na rua, na indústria e na mídia, e quase não aparece no questionamento teórico das cabeças pensantes. Esfera ontológica e socialmente inferior, não merece a investigação problemática; questão superficial, desencoraja a abordagem conceitual; a moda suscita o reflexo crítico antes do estudo objetivo, é evocada principalmente para ser fustigada, para marcar sua distância, para deplorar o embotamento dos homens e o vício dos negócios: a moda é sempre dos outros (LIPOVETSKY, 2009: 9). 
Apesar do possível "desprezo" por parte da academia, a moda assim como suas ramificações com a "indústria da moda" - tem uma origem distante que, com o passar dos séculos, ganhou forma e se estruturou no que hoje conhecemos como os grandes impérios da moda, as "grandes marcas". Dentre essas grandes marcas de luxo, de alta costura, está a Maison Yves Saint Laurent (YSL ou somente Saint Laurent), que leva o mesmo nome de seu fundador, o estilista francês Yves Saint Laurent.

Yves Henri Donat Mathieu-Saint Laurent nasceu em Orã, na Argélia, no período em que o país era uma colônia francesa, no dia 1 de agosto de 1936. Era filho de um homem de negócios, mas sua paixão pela moda foi influenciada e incentivada por sua mãe e aos 17 anos se mudou para Paris com o intuito de estudar. Venceu um concurso internacional de moda pela criação de um vestido coquetel, o que veio a impressionar o diretor da Vogue Paris na época, Michel de Brunhoff, e o estilista Christian Dior, que o contratou como assistente.

Após a morte de Dior, Saint Laurent herdou o controle criativo da Maison Dior. Sua primeira coleção foi muito bem recebida pelo público do período, o que fez com que Yves ganhasse o prêmio Neiman Marcus, um marco em sua carreira que possibilitou a abertura de muitas oportunidades na indústria da moda.

Mesmo alcançando sucesso em sua carreira, foi convocado pelo exército francês para lutar durante a Guerra de Independência da Argélia, o que fez com que sofresse um colapso nervoso após 20 dias servindo, sendo submetido a fortes tratamentos psiquiátricos, ficando afastado e 
posteriormente desligado da Maison Christian Dior. Yves Saint Laurent nunca falou abertamente sobre este período de sua vida, mas utilizava de seus desfiles para expor seus pontos de vista sobre assuntos mais polêmicos, como a participação da França em suas diversas guerras.

Entendendo a importância da indumentária no contexto historiográfico e o impacto de Yves Saint Laurent no universo da moda, este artigo busca analisar a criação de uma das peças mais icônicas da alta costura e da carreira do estilista, o le smoking, com o intuito de compreender o que levou o couturier à criação do design no final da década de 1960 na França.

\section{A França de 1960 e sua raízes no mundo da moda}

A França desde o início tem uma forte importância e influência no mundo da moda, principalmente no âmbito da moda de alta costura (haute couture), que consiste na criação de peças sob medida, produzidas em poucas unidades e confeccionadas inteiramente na França, já que foi no país que a chancela e o conceito de haute couture surgiu em meados do século XIX, como destaca Lipovetsky em seu livro:

Outono de 1857-inverno de 1858: Charles-Frédéric Worth funda, na rue de la Paix em Paris, sua própria casa, primeira da linhagem do que um pouco mais tarde será chamado de Alta Costura. [...] a verdadeira originalidade de Worth, de quem a moda atual continua herdeira, reside em que, pela primeira vez, modelos inéditos, preparados com antecedência e mudados frequentemente, são apresentados em salões 
luxuosos aos clientes e executados após escolha, em suas medidas (LIPOVETSKY, 2009: 82).

Hoje a chancela da alta costura é protegida internacionalmente por lei e o título somente pode ser concedido às Maisons francesas pela Fédération de la Haute Couture et de la Mode, um órgão do governo que está ligado à Câmara do Comércio e da Indústria do país. Somente ateliês autorizados podem usar da denominação de alta costura. Atualmente 17 Maisons são consideradas membros permanentes da Federação e 8 como membros correspondentes.

Lipovetsky ainda aponta o que fez com que a alta costura se diferenciasse e ganhasse tamanho significado dentro da moda:

Incontestavelmente, a Alta Costura é a instituição mais significativa da moda moderna; só ela precisou mobilizar permanentemente o arsenal das leis a fim de se proteger contra o plágio e os falsificadores, só ela despertou debates acalorados, só ela gozou de uma celebridade mundial, só ela se beneficiou da publicidade regular e acelerada da imprensa especializada (LIPOVETSKY, 2009: 81).

Para entender a moda discutida e estudada do século XX e que porventura chega até os dias atuais, é necessário buscar suas bases. Lipovetsky descreve o conceito de moda de cem anos e sua origem:

Foi ao longo da segunda metade do século XIX que a moda, no sentido moderno do termo, instalou-se. Certamente nem tudo então é absolutamente novo, longe disso, mas, de maneira evidente, apareceu um sistema de produção e de difusão 
desconhecido até então e que se manterá com uma grande regularidade durante um século. [...] Da metade do século XIX até a década de 1960, momento, com efeito, em que o sistema começa a fender-se e a readaptar-se parcialmente, a moda vai repousar sobre uma organização a tal ponto estável que é legítimo falar de uma moda de cem anos, primeira fase da história da moda moderna, seu momento histórico e sublime (LIPOVETSKY, 2009: 79).

As mudanças e readaptações que ocorreram na década de 1960 são significativas e refletem o período de estabilidade e crescimento (mesmo que por vezes superficial) que a humanidade vinha vivenciando desde o fim da $2^{\text {a }}$ Guerra Mundial. A partir da intensa busca das grandes potências pelo avanço tecnológico e econômico, possibilitaram um "bem-estar coletivo" que derivou em novos movimentos sociais, novos questionamentos e modos de vida.

A realidade francesa da década de 1960 é a de um país que se recupera do desgaste vivido pela participação em diversas guerras desde o século XIX, dentre elas a $1^{\mathrm{a}}$ e a $2^{\mathrm{a}}$ Guerra Mundial, como aponta Jean-François Sirinelli (2014: 9)

até 1962 , a história francesa poderia, sob muitos aspectos, se resumir nesta fórmula de impacto: a guerra sempre recomeçada. Por quase um século, de 1870 a 1962, a marca desta foi profunda na vida e na consciência da comunidade francesa.

Alguns destes conflitos não foram vivenciados em território francês, nem em suas grandes metrópoles, como a guerra da Indochina e da Argélia, 
fator que acabou por não influenciar a vida dos franceses diretamente, como destaca Sirinelli (2014), mas, que somada à constante realidade de conflitos sucessivos do país, acabou por se enraizar e se mesclar na identidade nacional, instaurando assim uma realidade complexa entre os franceses e a guerra. De maneira que a constante da guerra, no imaginário francês, simbolicamente podia ser associada ao cerne da sociedade.

Após 1945, um crescimento contínuo sem precedentes pelas próximas três décadas marcou o país e ficou conhecido como os Trinta Gloriosos, o que acabou por marcar também grandes mudanças e transformações na sociedade francesa. Roger Price (2016) descreve em seu livro a maneira como o investimento econômico interno durante o período mesmo com problemas relacionados à inflação - serviram para impulsionar a economia e destacar o país internacionalmente, trazendo assim mudanças estruturais e novas oportunidades diante das crescentes pressões competitivas da época. A década de 1960 em específico ficou marcada por uma maior abertura e ruptura da realidade existente até então, como Price (2016: 355) apresenta em sua continuação:

A década de 1960 constituiria os "anos de ruptura". O crescimento econômico facilitou a mobilidade geográfica e social. As cidades recuperaram seu dinamismo e acelerou-se o êxodo do campo. Os valores religiosos e morais tradicionais foram questionados como parte de uma revolução dos "gostos e expectativas". Os indicadores mais claros do tamanho das mudanças são as estatísticas sobre estruturas socioprofissionais, as quais revelam um rápido declínio da população empregada na agricultura, estabilidade no número de trabalhadores industriais, crescimento do número de 
trabalhadores de escritório e um declínio no número de empregadores por causa do crescimento substancial das categorias profissionais e gerenciais, contribuindo para $\mathrm{o}$ fortalecimento das classes médias.

Com o surgimento de novas oportunidades no país, novos meios de produção e comércio também adentraram a economia francesa, por uma busca mais competitiva e similar a modelos estadunidenses, a produção mais rápida e em maior quantidade ganhou força no período.

Dentro destes parâmetros, com uma economia em constante crescimento e com uma sociedade de consumo fortalecida e revigorada, se encaixa a abertura da primeira prêt-à-porter ${ }^{2}$ da Maison YSL em 1966 em Paris, a Rive Gauche, originalmente às margens esquerda do rio Sena. A popularização da prêt-à-porter foi um dos grandes marcos dentro da indústria da moda, sendo criada originalmente por Pierre Cardin de 1959, mas que ganhou fama e adeptos dentro e fora da França com Yves Saint Laurent e a Rive Gauche, como destacam as notícias do The New York Times do período, que apontam certa ansiedade e expectativa internacional para a inauguração da loja do estilista.

Rive Gauche apresentava uma realidade de consumo mais acessível às classes ascendentes do período, de forma que Saint Laurent usou sua prêt-à-porter como um laboratório de ideias, criando também coleções

2 “Expressão lançada na França por Jean Claude Weill em 1949, a partir da expressão norte-americana ready to wear, pode ser considerada uma verdadeira revolução, pois muda completamente a lógica da produção industrial." (CALANCA, 2011: 203). 
diferentes das até então conhecidas em sua Maison e não simplesmente recriando versões mais acessíveis de suas peças de alta costura.

\section{St. Laurent, o le smoking e as mudanças sociais do período}

O contexto da década de 1960 se apresenta como um período marcante e de grande importância histórica, seja por via de seus diversos acontecimentos sociais, culturais ou econômicos. Dentro da França não foi diferente, tomando como exemplo acontecimentos do período como o início dos Vinte Decisivos (1965-1985), além do movimento de Maio de 68 e a crise política em que o país se encontrava sob o comando de seu presidente, o general Charles de Gaulle.

Nesta conjuntura, a indústria da moda necessitou apresentar novos formatos e opções para as demandas crescentes da sociedade do período, como pode ser visto por meio da cobertura jornalística de Gloria Emerson de 23 de julho de 1968 na matéria do The New York Times "After the 'Revolution', Couture asks questions', na qual a jornalista questiona o posicionamento de alguns estilistas sobre os acontecimentos de Maio de 1968 e de que forma eles seriam refletidos em coleções futuras, além de alfinetar a possibilidade destas coleções serem vistas somente como uma forma de ganhar dinheiro em cima de movimentos sociais.

As mudanças culturais e econômicas do período apresentavam dois contrapontos importantes; de um lado uma crescente classe média (jovem) que ganhava poder aquisitivo, como descreve a matéria do The New York Times de 28 de dezembro de 1965, "France is getting younger to the cry of 
'I Am Free" e buscava, no contexto dos países europeus em recuperação pós-guerra, uma maior internacionalização de certos aspectos na sociedade - aqui tomando como exemplo aspectos dentro da indústria da moda.

Por outro lado, alguns setores mais tradicionais como o das Maisons francesas enfrentavam crises com o aumento nos preços, nos custos de produção e manutenção, além de uma demanda de produção mais rápida do que a existente até o momento, para suprir uma nova geração de consumidores que tinham como base a classe média trabalhadora e sua nova valorização do tempo, seguindo o modelo estadunidense de "ready to wear" (o prêt-à-porter em francês), fato discutido nas manchetes de 14 de julho de 1965, "St. Laurent sees growth in prestige, but not size" e 12 de setembro de 1965, "After Courrèges, what futures for Haute Couture?" do jornal The New York Times. Tais vertentes de consumidores tomavam como base a crescente influência mundial dos Estados Unidos após 1945 e seu american way of life.

Todos estes fatores eram refletidos nas prioridades pessoais do período, o que, por sua vez, acabava por colocar toda a estrutura das Maisons e suas criações em grande risco. Isso é enfatizado por Mara Rubia Sant'anna-Muller (2011: 115) quando coloca:

Os anos pós-guerra, aos poucos, elaboraram uma nova sociedade, cujos valores eram representados com fragilidade pela Haute Couture francesa tradicional. [...] Contudo, na medida em que os anos 60 chegaram, observa-se modificações significativas nas tendências que todos os grandes costureiros apresentaram. Em grande parte, isso decorreu diretamente do falecimento ou afastamento do criador da direção de sua 
Maison e a chegada de outros profissionais, que os substituíram. Porém, o fato de maior relevância está no redimensionamento do significado do papel da Haute Couture na produção da elegância idealizada, o que exigiu de seus novos profissionais outros perfis. Tal contexto exigiu das Maisons maior flexibilidade face aos novos grupos sociais que se constituíam a partir de outros poderes aquisitivos no cenário mundial. Na dança do poder, foi preciso abrir espaço para novos pares.

Neste contexto social se encontrava Yves Saint Laurent, o mais jovem couturier do período, considerado por alguns um "jovem prodígio" dentro da alta costura francesa. Com a abertura de sua própria Maison em 1961 obteve uma maior liberdade para experimentar e criar tendências, fato que não era tão apreciado quando trabalhava como diretor criativo da Dior.

Sua primeira grande criação que acabou ganhando destaque dentro e fora da França e atingiu o mercado estadunidense - um mercado importante a ser "conquistado" até os dias atuais quando se trata de comércio e consumo - foi o seu vestido Mondrian, criado para sua coleção de Outono-Inverno de 1965 e inspirado nas obras de Piet Mondrian, conforme observado em matérias do The New York Times e da Vogue Itália do período. O vestido também se tornou um dos símbolos da indústria da moda de $\mathrm{Op} \mathrm{Art}^{3}$ (Arte Óptica) do período.

${ }^{3}$ Refere-se a um movimento artístico que teve seu auge entre 1965 e 1968. Os artistas envolvidos nesta vertente realizam pesquisas que privilegiam efeitos óticos, em função de um método ancorado na interação entre ilusão e superfície plana, entre visão e compreensão, dialogando diretamente com o mundo da indústria e da mídia (publicidade, moda, design, cinema e televisão), os trabalhos da $O p A r t$ enfatizam a percepção a partir do movimento do olho sobre a superfície da tela. 
Foi uma das primeiras peças de sua criação que atingiram as grandes massas consumidoras, sendo copiado diversas vezes por grandes lojas de varejo pela Europa e América do Norte, como é destacado na entrevista do The New York Times de 12 de novembro de 1965, “'I hate Mondrian now', St. Laurent says", em que a jornalista Angela Taylor entrevista o estilista em sua passagem por Nova York para promover seu perfume "Y" e Saint Laurent reforça, ainda que de forma bem-humorada, a pressão e o desgaste que a popularização do vestido Mondrian trouxeram, tanto pelas diversas cópias em si, mas também pela expectativa colocada para as suas próximas coleções.

Parte da popularidade do vestido pode ser analisada a partir da proposital representação do quadro de Mondrian no design, que passou a adquirir uma nova importância, um novo significado, indo além de um simples vestido ou peça de roupa e se elevando - até certo ponto - a um conceito de obra de arte.

A receptividade e a popularidade de Yves Saint Laurent no mundo da moda sofreram certa variação conforme o país. Ainda que de maneira geral mantivesse o prestígio que todos os estilistas franceses de alta costura carregavam e ainda carregam até hoje, o seu estilo, suas escolhas e criações possuíam mais impacto e importância no mercado estadunidense, além do mercado francês.

Esse fato era comprovado a partir de suas vendas e cobertura midiática do período, tomando como exemplo a matéria de Georgina Howell de 7 de agosto de 1966, "Real Paris people and latest collections" 
para o The Guardian, na qual a jornalista descreve, a partir de sua viagem para Paris, o sentimento de "não pertencimento" quando analisa as roupas criadas pelos estilistas e de como "todas as pessoas são bem vestidas em Paris", quando comparado com a sua realidade em Londres.

De tal forma, muitos críticos apontavam como o estilista "criava para o mercado estadunidense" e para as jovens "yé-yé", como é possível verificar na matéria do The Guardian de 6 de agosto de 1967, "HERS: Runners-up win at Paris", sendo apontado que sua moda por vezes não representava o mercado europeu como um todo, já que este ainda carregava fortemente características mais tradicionais e clássicas, em especial no vestuário feminino de mulheres mais velhas.

Saint Laurent apostava em criações mais andróginas e "libertadoras" para o guarda-roupa feminino a cada coleção, seja por meio de vestidos não acinturados, leves, o uso de calça e shorts, blusas e vestidos com transparência ou a adaptação de peças estritamente masculinas para o guarda-roupa feminino, como foi o caso do le smoking, criado para a "Pop Art Collection" do Outono-Inverno de 1966.

O le smoking se baseava na adaptação do terno masculino mantendo suas premissas de criação - para o uso no guarda-roupa feminino. Yves Saint Laurent o apresentou com a proposta de uso social formal, tal qual utilizado por homens. Era composto por uma calça social preta de

\footnotetext{
${ }^{4}$ Termo originado na França para exemplificar a juventude efervescente do período de 1960. Muito associada a boybands da época, como Os Beatles e a "beatlemania". O desenvolvimento desta cultura estaria ligado a uma conquista de autonomia dos adolescentes no seio da família e da sociedade.
} 
corte reto, uma camisa branca com babados por baixo de um blazer pouco acinturado com quatro bolsos, três botões e finalizado com uma fita de cetim preta formando um laço onde costumeiramente ficam as gravatas no modelo masculino.

A importância da criação foi logo percebida pelo couturier, de forma que o design se manteve como uma peça fixa em todos os desfiles de suas coleções desde 1966 até 2002, quando o estilista se aposentou de sua Maison. O le smoking passava por uma releitura a cada coleção, sendo "reinventado" com base nas tendências e propostas que Saint Laurent desejava apresentar naquele desfile, porém, buscando manter em sua essência as premissas de um terno masculino adaptado para o corpo e o guarda-roupa feminino.

Segundo a matéria de 5 de agosto de 1966 do The New York Times, "A nude dress that isn't: Saint Laurent in a new, mad mood", de Gloria Emerson, a influência para a criação do design teria vindo de Niki de Saint-Phalle, uma pintora, escultora e cineasta de origem francesa com quem Saint Laurent havia trabalhado no início daquele ano em uma produção de balé de Roland Petit. Vale o apontamento de que mesmo que Saint-Phalle seja de origem francesa, viveu por muitos anos nos Estados Unidos, obtendo dupla-cidadania, de forma que a jornalista a apresenta como estadunidense em sua matéria, dando assim o entendimento da influência de criação do le smoking aos EUA, como é observado em sua fala: 
Niki de Sant-Phalle, artista americana radicada no país, foi a que mais influenciou Saint Laurent, embora ainda não saiba. A senhorita Saint-Phalle, cujas estátuas de mulheres enormes são chamadas de 'Nanas', conheceu o designer no início deste ano, quando foi co-criadora na decoração do balé de Roland Petit. Agora Saint Laurent copiou seu terninho "black tie" em veludo e lã (EMERSON, 1966). ${ }^{5}$

Porém, o estilista descreve sua inspiração a partir de uma foto de Marlene Dietrich usando roupas masculinas:

Fiquei profundamente impressionado com uma fotografia de Marlene Dietrich vestindo roupas masculinas, disse Yves Saint Laurent. Um smoking, um blazer ou uniforme de oficial da Marinha - uma mulher vestida de homem deve estar no auge de sua feminilidade para lutar contra um hábito que não é dela. (LAURENT apud THE NEW YORK TIMES..., [20--]: [1], tradução nossa). ${ }^{6}$

Saint Laurent descrevia que o le smoking poderia ser caracterizado como "uma peça indispensável com a qual ela (a mulher) se sentiria sempre estilosa, visto que se trata de uma roupa de estilo e não de moda. As modas

\footnotetext{
${ }^{5}$ Texto original: "Niki de Sant-Phalle, an american artist living in this country, has had the best influence of all on Saint Laurent, although she does not yet know it. Miss Saint-Phalle, whose statues of oversize women are called Nanas, met the designer earlier this year when she was co-designer of the décor of a Roland Petit ballet. Now Saint Laurent has copied her "black tie" trouser suit in velvet and in wool".

${ }^{6}$ Texto original: "I was deeply struck by a photograph of Marlene Dietrich wearing men's clothes," said Yves Saint Laurent. "A tuxedo, a blazer or a naval officer's uniform - a woman dressed as a man must be at the height of femininity to fight against a costume that isn't hers".
} 
Cadernos de Clio, Curitiba, v. 11, nº. 1, 2020

passam, o estilo permanece""7 (LAURENT apud MUSÉE..., [20--]: [1], tradução nossa). Diana Crane analisa em sua obra sobre como estilos alternativos de vestuário foram importantes para a ressignificação simbólica e independência feminina no contexto social:

O estilo alternativo de vestuário, que incorporava peças de roupas masculinas à vestimenta feminina, representava, consciente ou inconscientemente, uma forma de resistência ao estilo de vestuário dominante. [...] esse estilo representou uma espécie de inversão simbólica da mensagem dominante de vestuário feminino ao associá-lo ao masculino. Através de um processo de inversão simbólica, itens ligados à indumentária masculina ganharam novos significados - mais especificamente, a independência feminina - que desafiaram as fronteiras de gênero (CRANE, 2009: 265).

A princípio a criação do le smoking não foi bem aceita pela clientela de alta costura, que normalmente era composta por mulheres ricas, mais velhas e tradicionalistas em sua forma de vestir, fato que fez com que somente uma peça fosse vendida de início. Somente quando Saint Laurent levou o modelo para sua loja prêt-à-porter - Rive Gauche que o design ganhou força e popularidade, acontecimento que é possível de ser observado na matéria do The New York Times de 16 de setembro de 1968, de Bernadine Morris, "Saint Laurent has a new name for Madison Ave. Rive Gauche", em que o couturier aponta as diferentes recepções da peça:

7 Texto original: "For a woman, the tuxedo is an indispensable garment in which she will always feel in style, for it is a stylish garment and a not a fashionable garment. Fashions fade, style is eternal'. 
Eu primeiro criei o 'le smoking' para a coleção de alta-costura, disse ele, mas ninguém comprou. Então, eu o trouxe para o ready-to-wear e foi um grande sucesso. Foi uma boa experiência para mim. Vi que o espírito de quem compra no ready-to-wear está mais adaptado à vida de hoje, mais receptivo às mudanças (LAURENT, 1968). ${ }^{8}$

A grande aceitação do design pelo público consumidor de sua loja prêt-à-porter desde o início tem como justificativa a base econômica e a faixa etária de sua clientela, já que sua maioria era composta por mulheres jovens, de classe média que já estavam inseridas no mercado de trabalho e possuíam uma maior adaptação a novas tendências de moda, fatores que são observados nas matérias do The New York Times do período.

Um dos marcos que veio a fortalecer o le smoking como uma das peças icônicas da moda para a contemporaneidade foi a publicação de uma matéria da Vogue Paris de setembro de 1975, intitulada "Haute Couture 1975-1976" que apresentava um editorial fotografado por Helmut Newton, um renomado fotógrafo de moda. Dentre os designers escolhidos para o editorial estavam algumas peças da Maison Yves Saint Laurent, dentre elas o le smoking criado para aquela estação.

As fotografias que utilizaram o le smoking foram feitas à noite em becos nas ruas de Paris, nas quais a modelo foi representada em um visual

\footnotetext{
${ }^{8}$ Texto original: "I first did 'le smoking' for the couture collection" he said, "but nobody bought it. Then I brought it out in ready-to-wear and it was a great success. It was a good experience for me. I saw the spirit of the people who bought ready-to-wear is more adapted to the life of today, more receptive to change".
} 
andrógino, com características e hábitos tradicionalmente vistos como masculinos, seja por seu cabelo curto, estar sem maquiagem, fumando, em uma pose fechada e séria como eram feitas a maioria das fotos publicitárias de ternos masculinos.

O editorial foi considerado um marco no período, tanto para a carreira de Yves Saint Laurent, o fortalecimento e a reafirmação de sua criação quase uma década depois, quanto para a forma de representação feminina e de feminilidade ao utilizar o le smoking em uma proposta mais andrógina e "fora dos padrões" de beleza femininos.

Saint Laurent reforçou, através de seu consistente uso de calças em desfiles, o processo transformatório no guarda-roupa das mulheres ocidentais do período, principalmente no uso de calças sociais, que eram vistas majoritariamente como parte do vestuário masculino até então, ao contrário de calças jeans que eram mais aceitas, principalmente no cotidiano de mulheres jovens e/ou trabalhadoras desde a década de 1950.

O uso de calças sociais no dia a dia feminino da época era visto como mais uma "desnecessária moda passageira", algo de uma estação que seria esquecido dentro do guarda-roupa. Também não era considerado como uma roupa aceitável para que se frequentasse certos estabelecimentos, como por exemplo restaurantes. Neles, ocorriam histórias como a da socialite Nan Kempner, que foi barrada de entrar em um famoso restaurante em Manhattan, o La Côte Basque, por estar usando o le smoking, de maneira que, para conseguir entrar, teve que se despir da calça e transformar o blazer em um minivestido. 
Reportagens - como a do The New York Times de 10 de abril de 1967, "The continuing story of the Pants Suit: will it survive?", por Marylin Bender - apontam a visão da sociedade do período sobre o controle do feminino, seja do corpo, da postura, da vestimenta ou de qualquer outro aspecto dentro deste ideal de mulher. Desta forma, na matéria, a fala de uma das entrevistadas, Ellen Brooke (1967), reitera este pensamento:

Um grupo inteiro da humanidade ainda não começou a receber a mensagem. O terninho social tem um bom caminho a percorrer ainda. Mas ao menos que você tenha bom gosto e um bom traseiro você não deve usá-lo. Uma mulher sempre deve manter a elegância e graça ao se movimentar. ${ }^{9}$

Assim também ocorre na reportagem de 7 de outubro de 1968, "Even the restaurants concede that pants are fashionable", de Bernadine Morris para o The New York Times. Nesta reportagem, um dos apontamentos feitos pela jornalista quanto à popularização e à possível aceitação do uso de calças versa sobre a insatisfação masculina: "as objeções mais vociferantes vêm de homens que gostam de olhar para as pernas e consideram as minissaias a moda mais sensata"10 (MORRIS, 1968). Outro ponto destacado na reportagem é o receio por parte das mulheres de não parecerem femininas usando calças, de forma que deixariam de usar por

\footnotetext{
${ }^{9}$ Texto original: "A whole coterie of humanity hasn't begun to get the message yet. The pants suit has quite a way to go. But unless you have taste and a good behind you shouldn't wear it. A woman should be a thing of grace in movement always". ${ }^{10}$ Texto original: "The most vociferous objections come from men who like to look at legs and found miniskirts the most sensible fashion going".
} 
reprovação masculina, como apontava Monrie Meyerson - uma engenheira industrial - quando fala que "se meu marido se opusesse, eu não usaria".

Michelle Perrot, em sua obra "Minha história das mulheres", cita Georges Duby em sua análise sobre como a iniciativa (e o poder) masculinos afetam a maneira como as mulheres se enxergam e buscam representação:

[...] a força da iniciativa masculina que reduz as mulheres a espectadoras, mais ou menos submissas, de si mesmas. "As mulheres não representavam a si mesmas", escreve ele. "Elas eram representadas. [...] Ainda hoje, é um olhar de homem que se lança sobre a mulher" e se esforça para reduzi-la ou seduzi-la (PERROT, 2007 apud DUBY, 1992: 192).

A moda, em especial a moda de alta costura do período, foi de grande importância para a disseminação e a aceitação de novos estilos e propostas de vestimentas no guarda-roupa feminino. Crane aponta, em especial, a importância da haute couture na aceitação e posteriormente popularização, do uso de calça pelas classes média e alta quando descreve que "a calça foi aceita pelas mulheres de classe operária durante a guerra, e apenas muito mais tarde, na década de 1960, pelas de classe média, depois de aparecerem nas coleções de estilistas franceses" (CRANE, 2009: 257).

Desta forma, o contexto social favorável encontrado em meados da década de 60 aos movimentos sociais - em especial o início da segunda onda do movimento feminista, que "explodiria" na década de 1970 nos Estados Unidos e na Europa -, os ideais e os questionamentos quanto ao 
"ser mulher", seu papel na sociedade e a busca por igualdade de direitos influenciaram na modificação de diversos aspectos e costumes na sociedade que, por sua vez, vieram a ser representados em diferentes formatos, um deles sendo por meio do vestuário.

Yves Saint Laurent marcou seu nome como um dos estilistas "visionários" que entendiam e buscavam, por meio de suas criações, oferecer novas bases de expressão para as mulheres do período, valendo-se da ressalva de que suas propostas e influências se mantinham originalmente no âmbito de mulheres de classes média, média-alta e alta. Ao mesmo tempo, porém, entendia que, a partir da popularização de seus designs, com sua reprodução alcançando os grandes mercados de moda e, assim, as grandes massas populares, com as lojas de varejo, também seus ideais e suas propostas chegavam para o guarda-roupa feminino mais generalizado.

\section{Considerações finais}

O legado deixado por Yves Saint Laurent avança além da criação do le smoking, passando pelo vestido Mondrian, as coleções Safari e Scandal e a valorização do uso de transparências em suas roupas. Simboliza, por meio do vestuário, uma nova visão para o vestir feminino e apresenta, a partir da moda, oportunidades de redefinir padrões.

Em especial, o le smoking ganha destaque por ressignificar um vestuário estritamente associado ao masculino, que representava a detenção do poder, influência social e econômica da época - homens de negócios, influentes e tradicionais do período, podendo ser exemplificados por 
corretores da bolsa de valores de Nova York, trabalhadores de grandes empresas em centros urbanos ou simplesmente por donos dos meios de produção.

Desta forma, o terno em si como uma peça de roupa não sofre modificações em sua importância e simbologia como um ícone de status e poder por aqueles que o vestem, mas ganha uma ampliação e nova aceitação social para serem utilizados, a partir daquele período, também por mulheres.

Também é necessário compreender a importância que teve a Rive Gauche e o formato prêt-à-porter na disseminação e popularização do le smoking para um grande número de mulheres de diferentes classes sociais, além das tradicionais consumidoras da haute couture do período. O público jovem consumidor, observador de tendências e frequentador de lojas no formato ready to wear, ganhou força e importância no período, de tal modo que passou a ditar e influenciar os novos passos da indústria da moda.

As décadas de 1960 e 1970, como um todo, são marcadas por diversas quebras de paradigmas, revoluções e mudanças sociais ao redor do mundo. As modificações e popularizações no guarda-roupa do período puderam ocorrer, sendo aceitas e disseminadas principalmente por acontecerem nesta época, o que pode ser entendido como "uma tempestade perfeita”, já que os movimentos sociais e a busca por mudanças, neste caso femininas, já haviam ocorrido anteriormente diversas vezes, conquistando outros direitos - que vieram a abrir caminho para estas conquistas - desta maneira não podendo ser delimitadas somente a este período, já que se 
entende que o questionamento, busca por aceitação e a transitoriedade são uma constante humana.

\section{Referências}

BENAÏM, Laurence. Yves Saint Laurent: uma biografia. São Paulo: Siciliano, 1994.

CALANCA, Daniela. História social da moda. 2. ed. São Paulo: Editora Senac, 2011.

CRANE, Diana. A moda e seu papel social: classe, gênero e identidade das roupas. 2. ed. São Paulo: Editora Senac, 2013.

FEDERATION DE LA HAUTE COUTURE ET DE LA MODE. Haute Couture: haute couture members. France, Paris, [20--]. Disponível em: $<$ https://fhcm.paris/en/haute-couture-2/>. Acesso em: 19 jan. 2021.

LIPOVETSKY, Gilles. O império do efêmero: A moda e seu destino nas sociedades modernas. São Paulo: Companhia das Letras, 2009.

MUSÉE YVES SAINT LAURENT PARIS. First tuxedo: related to fashion. França: Paris, [20--]. Disponível em: $<$ https://museeyslparis.com/en/biography/premier-smoking $>$. Acesso em: 9 set. 2020.

. Rive Gauche: related to haute couture house. France: Paris, [20--]. Disponível em: $<$ https://museeyslparis.com/en/biography/saint-laurent-rivegauche $>$. Acesso em: 5 set. 2020.

PERROT, Michelle. Minha história das mulheres. São Paulo: Contexto, 2007.

PESAVENTO, Sandra J. Em busca de uma outra história: imaginando o imaginário. Revista Brasileira de História, São Paulo, v. 15, n. 29, p. 9-27, 1995.

Disponível

em: 
$<$ https://www.anpuh.org/revistabrasileira/view?ID_REVISTA_BRASILEIR $\mathrm{A}=14>$. Acesso em: 14 nov. 2020.

PRICE, Roger. História concisa da França. 1. ed. São Paulo: Edipro, 2016.

RAINHO, Maria do Carmo. A moda como campo de estudos do historiador: balanço da produção acadêmica no Brasil. In: COLÓQUIO DE MODA, 11, 2015, Curitiba. Disponível em: $<$ http:/www.coloquiomoda.com.br/anais/Coloquio\%20de\%20Moda\%20-\% 202015/ARTIGOS-DE-GT/GT06-MODA-E-CULTURA/GT-6-A-MODACOMO-CAMPO-DE-ESTUDOS-DO-HISTORIADOR.pdf $>$. Acesso em: 10 set. 2020.

SANT'ANNA-MULLER, Mara Rubia. Prêt-à-Porter, discussões em torno de seu surgimento e relação com a Alta-Costura francesa. Projética Revista Cientifica de Design, Universidade de Londrina, v. 2, n. 2, p. 114-127, dez. 2011. DOI. 10.5433/2236-2207.2011v2n2p114. Disponível em: <http://www.uel.br/revistas/uel/index.php/projetica/article/view/8856>. Acesso em: 20 jul. 2020.

SHARDLOW, Estella. Business Insider. Disponível em: $<$ https://www.businessinsider.com/ysls-greatest-fashion-hits-2011-8>. Acesso em: 21 out. 2020.

SIRINELLI, Jean-François. Abrir a História: novos olhares sobre o século XX francês. 1. ed. São Paulo: Autêntica Editora, 2014.

THE Guardian Archives: the largest online newspaper archive. Disponível em: <https://theguardian.newspapers.com/>. Acesso em: 01 set. 2020.

TIMES Machine. Disponível em: $<$ https://www.nytimes.com/search/?srchst=p>. Acesso em 01 set. 2020.

VOGUE Itália Archive. Disponível em: $<$ http://archivio.vogue.it/archivio $>$. Acesso em: 26 ago. 2020.

VOGUE PARIS. Haute Couture 1975-1976. Paris, n. 559, p. 144, set. 1975. 
Cadernos de Clio, Curitiba, v. 11, nº. 1, 2020

Recebido em: 17/02/2021 Aceito em: 15/04/2021 